\title{
Optimizing Stem Cell Mobilization: Lessons Learned
}

Pamela S. Becker, MD, PhD

\begin{abstract}
Granulocyte colony-stimulating factor is the pivotal component of mobilization regimens and the growth factor most often used for peripheral blood progenitor cell collections. When used alone or after chemotherapy, products with adequate yields of $\mathrm{CD} 34^{+}$cells are obtained after leukapheresis, resulting in optimal blood count recovery after transplant. For patients who have had extensive prior treatment with chemotherapy and/or radiation, or treatment with specific agents, the yields may be limited. For these patients, plerixafor in combination with growth factor can be used to augment progenitor cell yield and ensure successful collection of target goals, with preservation of the integrity of the graft. Progenitor cells can similarly be collected by leukapheresis from patients for autologous use and from allogeneic donors, after a period of growth factor administration. Many chemotherapy regimens can be used before growth factor administration that serve a dual role of reducing tumor burden and enhancing the progenitor cell collection. Given modern methods, a high success rate exists for procurement of adequate stem cell products. (J Natl Compr Canc Netw 2014;12:1443-1449)
\end{abstract}

\section{Introduction}

\section{Retention and Adhesion of Hematopoietic Stem} Cells in the Bone Marrow Microenvironment Hematopoietic stem cells (HSCs), capable of both selfrenewal and reconstitution of the blood cell lineages after transplantation, reside in the bone marrow in an environment known as the stem cell niche. Key components of the niche include endosteal osteoblasts, bone

From the Division of Hematology, Department of Medicine, University of Washington, and Clinical Research Division, Fred Hutchinson Cancer Research Center, Seattle, Washington. Submitted October 22, 2013; accepted for publication May 11, 2014.

Dr. Becker has disclosed that she has received research support from Sanofi and Amgen.

Correspondence: Pamela S. Becker, MD, PhD, University of Washington, Campus Box 358056, Institute for Stem Cell and Regenerative Medicine, 850 Republican Street N415, Seattle, WA 98109. E-mail: pbecker@seattlecca.org marrow endothelial cells, CXCL12 (formerly known as stromal cell-derived factor 1 [SDF-1])-abundant reticular cells, mesenchymal stromal cells, and perivascular leptin receptor positive cells. ${ }^{1-3}$ HSCs express the chemokine receptor, CXCR4, the receptor for CXCL12, and this interaction is critical for retention of HSCs in the marrow. ${ }^{4}$ Other receptors, such as integrins (eg, VLA-4 interaction with VCAM-1 $)^{5,6}$ and $\mathrm{CD} 44^{7}$, also play a role in the attachment within the marrow (Figure 1). HSCs exhibit physiologic circulation in the peripheral blood in small numbers, a process that can be augmented by pharmacologic dosing of cytokines and receptor antagonists. Granulocyte colony-stimulating factor (G-CSF) causes release of proteases, including neutrophil elastase, which cleaves CXCR4 and VCAM-1,,9 and elevated levels of metalloproteinases, including MMP-2 (that may be produced by mesenchymal stromal cells), ${ }^{10}$ MMP- $8,{ }^{11}$ and MMP-9,${ }^{12-15}$ which contribute to the release of stem cells to the circulation. Other physiologic systems contribute to control HSC mobilization, including the fibrinolytic system, ${ }^{16}$ bone remodeling, ${ }^{17}$ the sympathetic nervous system, ${ }^{18}$ and circadian rhythms. ${ }^{19}$ The small molecule AMD3100 was developed as a specific antagonist for CXCR4, which is also the coreceptor for entry of HIV into host cells. It was found to mobilize HSCs in the laboratory and in human subjects, and is now FDA-approved as plerixafor for stem cell mobilization in non-Hodgkin's lymphoma (NHL) and multiple myeloma. Several agents have been shown to mobilize stem cells in the laboratory, including pegylated G-CSF, antibody to VLA-4 (natalizumab), thrombopoietin, stem cell factor (SCF), macrophage inhibitory protein $1 \alpha$, interleukin 8 , and an CXCL12 analog, but only 3 drugs are FDA-approved for clinical use: G-CSF (filgrastim), granulocyte-macrophage colony-stimulating factor (GM-CSF; approved as sargramostim), and plerixafor. 


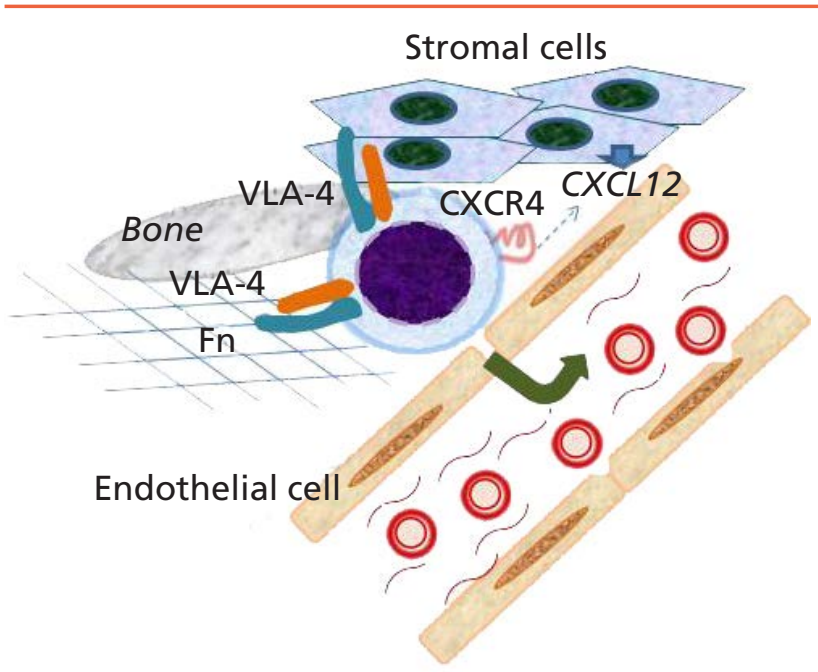

Figure 1 Stem cell mobilization. The hematopoietic stem cell resides in the endosteal niche, interacting with extracellular matrix components such as fibronectin (Fn), stromal cells, osteoblasts, and endothelial cells. Mobilization requires disruption of interactions, including integrins such as VLA-4 with ligands Fn or VCAM-1, CXCR4 migration toward CXCL12, c-kit with stem cell factor, and others, and then transendothelial migration to access the vasculature.

\section{Progenitor Cell Mobilization for Hematopoietic Cell Transplantation}

In the 1990s, the field of bone marrow transplantation shifted from use of bone marrow cells to mobilized peripheral blood progenitor cells (PBPCs). PBPC products contain HSCs, as proven by their ability to regenerate blood cell production after myeloablative chemoradiotherapy. Advantages of the mobilized cell products include ease of collection compared with operative procedures under anesthesia, more rapid recovery of blood counts after transplant, and more rapid immune recovery. In the allogeneic setting, the risk of chronic graft-versus-host disease (GVHD) is increased, but no difference in survival is associated with the use of PBPCs versus bone marrow. ${ }^{20}$ Appreciable data and algorithms now exist to optimize PBPC collections in both the autologous and allogeneic settings. ${ }^{21}$ Both growth factors, G-CSF and GM-CSF, can be used to mobilize stem cell products, and have also been used in combination with each other and with chemotherapy; pegfilgrastim also results in successful mobilization, although it is not currently approved for this indication. The advent of the use of plerixafor has markedly improved collections for patients with limited stem cell reserve. ${ }^{22}$ The potential side effects of the procedures associated with stem cell collec- tions have been thoroughly analyzed and catalogued, and their safety has been accepted. Lastly, the high number of successful PBPC transplants performed worldwide attests to the successful refinement of the procurement procedures and their standardization.

\section{Autologous Stem Cell Mobilization}

Mobilization can be performed after myelosuppressive chemotherapy regimens and growth factor administration or with growth factor alone. ${ }^{23,24}$ Both G-CSF and GM-CSF are FDA-approved for this indication, but G-CSF is more widely used. A target yield of CD34 ${ }^{+}$ cells in the progenitor cell product of 2.0 to $5.0 \times 10^{6}$ per kilogram weight of the recipient is the range that has been shown to result in adequate and prompt blood cell recovery. Several studies showed delayed neutrophil and platelet recovery if less than 2.0 or $2.5 \times 10^{6}$ $\mathrm{CD}^{+} 4^{+}$cells $/ \mathrm{kg}$ were infused, with increased platelet and red cell transfusion requirements. ${ }^{25-30}$ The usual dosing of G-CSF is in the range of 10 to $32 \mathrm{mcg} / \mathrm{kg} / \mathrm{d}$ in single or divided twice-daily doses (Table 1). Apheresis collections begin on day 4 or 5 when GCSF is used as a single agent. ${ }^{23,31}$

Comparable yields of $\mathrm{CD} 34^{+}$cells were obtained when high-dose G-CSF was used at $12 \mathrm{mcg} / \mathrm{kg} / \mathrm{d}$, or Dexa-BEAM (dexamethasone, carmustine, etoposide, cytarabine, and melphalan) followed by G-CSF was used as the regimen for mobilization, with an average yield of 5.3 versus $5.1 \times 10^{6} \mathrm{CD} 34^{+}$cells $/ \mathrm{kg}$, respectively, and a median of 2 collections for each. ${ }^{24}$ "Mega" doses of progenitor cells (for patients who collected and received infusions of $>8 \times 10^{6} \mathrm{CD} 34^{+}$ cells/kg) may confer an advantage, because "super mobilizers" were associated with a superior survival after (autologous) transplant for lymphoid malignancy in retrospective multivariate analysis, ${ }^{32}$ and more rapid engraftment of neutrophils and platelets. Improved relapse-free survival was seen, but the mechanism could not be elucidated. GM-CSF may also be used for mobilization, typically at a dose of $250 \mathrm{mcg} / \mathrm{m}^{2} / \mathrm{d}$, and has been used alone or sequentially daily for 3 days before G-CSF. ${ }^{21}$

Pegfilgrastim (polyethylene glycol-linked GCSF, or pegylated G-CSF), which has a longer halflife than G-CSF, has also been studied in clinical trials and comparable cell yields have been obtained, ${ }^{33,34}$ but mobilization is currently not an approved use. 
Stem Cell Mobilization

\section{Table 1 Essentials of Stem Cell Mobilization: Typical Dosing}

\section{Type of Donor \\ Standard autologous patient}

Poor autologous mobilizers (actual or predicted)

\section{Drug and Dose}

G-CSF alone: $10 \mathrm{mcg} / \mathrm{kg} / \mathrm{d}$ (up to $32 \mathrm{mcg} / \mathrm{kg} / \mathrm{d}$ ) via subcutaneous injection, daily or twice daily schedule; start to collect day 4 or 5. G-CSF is continued up to and including the day of leukapheresis

Chemotherapy (several regimens, depending on diagnosis and disease burden) + G-CSF: chemotherapy regimen then approximately 1 day after chemotherapy, start daily G-CSF at dose specified above until WBC count increases and $\mathrm{CD} 34^{+} / \mathrm{mcL}$ target is achieved, then start leukapheresis

High-dose G-CSF (20-32 mcg/kg/d on twice-daily schedule)

Chemotherapy + G-CSF (several regimens)

$\mathrm{G}-\mathrm{CSF}+\mathrm{GM}-\mathrm{CSF}$

Plerixafor + G-CSF (twice-daily schedule) with addition of plerixafor 0.24 $\mathrm{mg} / \mathrm{kg}$ via subcutaneous injection (if $\mathrm{CrCl}>50 \mathrm{~mL} / \mathrm{min}$, maximum dose 40 $\mathrm{mg}), 11$ hours before collection (eg, start on day 4 of G-CSF)

May give plerixafor daily for up to 4 consecutive days

"Just in time" in the case of a low CD34+ cell count: add plerixafor $0.24 \mathrm{mg} / \mathrm{kg}$ (if $\mathrm{CrCl}>50 \mathrm{~mL} / \mathrm{min}$ maximum dose $40 \mathrm{mg}$ ) 11 hours before collection time with continued G-CSF

Standard allogeneic donor
G-CSF $10 \mathrm{mcg} / \mathrm{kg} / \mathrm{d}$ (range, 10-16 mcg/kg/d) via subcutaneous injection, start to collect day 4 or 5

Abbreviations: $\mathrm{CrCl}$, creatinine clearance; G-CSF, granulocyte colony-stimulating factor; GM-CSF, granulocyte-macrophage colony-stimulating factor.

Mobilization using a combination of chemotherapy and growth factor provides the advantage of reducing tumor burden before transplant in addition to resulting in high yield and reduction of contamination of the progenitor cell product. The single chemotherapy drugs used in combination with G-CSF are most often high-dose cyclophosphamide 35,36 or high-dose etoposide. ${ }^{37}$ Combinations of these 2 agents, ${ }^{22}$ or other pairs of agents such as highdose etoposide and high-dose cytarabine, ${ }^{38}$ have also been used for mobilization. In addition, the more aggressive multiagent regimens, such as DHAP (dexamethasone, high-dose cytarabine, and cisplatin) and R-ICE (rituximab, ifosfamide, etoposide, and carboplatin) for lymphoma, ${ }^{39}$ or VTD-PACE (bortezomib, thalidomide, dexamethasone, cisplatin, doxorubicin, cyclophosphamide, and etoposide) for multiple myeloma ${ }^{40}$ and others can be adapted through the addition of daily G-CSF and used for chemomobilization and reduction of residual disease. The timing of collection after chemotherapy plus growth factor is delayed, usually until approximately day 11 or 12 or later, depending on the increase of the white blood count and the circulating CD34 cell count. Target CD34 cell concentrations may be used to ensure an adequate collection, and institutional variation exists regarding when the collection will begin, usually in the range of 5 to $20 \mathrm{CD} 34^{+}$cells/ $\mu \mathrm{L}$. One formula that can predict the expected number of $\mathrm{CD} 34^{+}$cells that may be collected is the following: blood volume processed $(\mathrm{L}) \times\left(\mathrm{CD} 34^{+}\right.$cells $/ \mu \mathrm{L} \times$ machine collection efficiency)/patient weight $(\mathrm{kg}) .^{5}$

\section{Strategy for Low-Yield Collection}

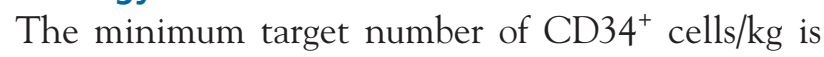
$2 \times 10^{6} / \mathrm{kg}^{26}$ below which sustained recovery of all blood counts may not occur. Certain factors, such as pretreatment with lenalidomide or fludarabinecontaining regimens, ${ }^{41,42}$ or extensive pretreatment with chemoradiotherapy (eg, >10 cycles of chemotherapy or radiation to bone marrow-containing regions), can interfere with the ability to obtain sufficient progenitor cell collections, possibly related to stem cell depletion or damage to the bone marrow microenvironment. A retrospective study at $\mathrm{Me}$ morial Sloan Kettering Cancer Center showed that $13 \%$ of patients with multiple myeloma did not meet the target of $5 \times 10^{6} \mathrm{CD} 34^{+}$cells $/ \mathrm{kg},{ }^{43}$ which was correlated with older age, lower platelet count, and use of single-agent G-CSF. Other studies have shown that as many as $18 \%$ to $26 \%$ of patients who undergo autologous transplant after mobilization with G-CSF alone do not reach target cell doses,,$^{27,28,44}$ and $17 \%$ to $47 \%$ of those who undergo mobilization with chemotherapy plus G-CSF do not achieve goals of col- 
Becker

lection. ${ }^{28-30}$ For many years, patients who had insufficient progenitor cell collections needed to undergo repeat mobilization with growth factor and/or chemotherapy and growth factor, and, if this failed, undergo bone marrow harvest. For example, high-dose G-CSF at $20 \mathrm{mcg} / \mathrm{kg} / \mathrm{d}$ and then $32 \mathrm{mcg} / \mathrm{kg} / \mathrm{d}$ in split dosing could salvage $88 \%$ of patients to a target yield of $2.5 \times 10^{6} \mathrm{CD} 4^{+}$cells $/ \mathrm{kg} .{ }^{45}$ Moreover, a combination of G-CSF $(10 \mathrm{mcg} / \mathrm{kg} / \mathrm{d})$ plus GM-CSF $(5 \mathrm{mcg} /$ $\mathrm{kg} / \mathrm{d}$ ) was comparable with $32 \mathrm{mcg} / \mathrm{kg} / \mathrm{d}$ of G-CSF, and resulted in $93 \%$ of patients achieving sufficient cell yield at a reduced cost. ${ }^{46}$

The CXCR4-CXCL12 chemotactic pathway is central to normal HSC homing and retention in the marrow. Plerixafor is a small molecule inhibitor of CXCR4, initially developed to block cellular entry of HIV1 and also shown to inhibit CXCR4 binding to CXCL12.47 It was later studied in healthy volunteers to demonstrate safety and efficacy in mobilizing hematopoietic progenitor cells. ${ }^{48}$ The side effects noted in this study included injection site symptoms (69\%), headache $(27 \%)$, perioral paresthesias $(31 \%)$, nausea (38\%), and sensation of abdominal distention (19\%). ${ }^{48}$ When used in combination with G-CSF, plerixafor could improve the yield of autologous stem cell collections in patients with $\mathrm{NHL}^{49}$ or multiple myeloma, ${ }^{50}$ and it was FDA-approved for this indication. For example, addition of plerixafor to G-CSF was compared with placebo plus G-CSF after a rest period of 7 days from initial failed mobilization in NHL. Only $7 \%$ of those who received plerixafor versus $38 \%$ of those who received placebo failed this remobilization, as defined as less than $0.8 \times 10^{6} \mathrm{CD} 34^{+}$ cells/kg in 2 days or less than $2 \times 10^{6} \mathrm{CD} 4^{+}$cells $/ \mathrm{kg}$ in 4 days. ${ }^{51}$ The dosing guideline recommends that it be administered 11 hours before the collection, but study of other administration times has shown satisfactory collections of $6 \times 10^{6}$ or more CD $34^{+}$cells/ $\mathrm{kg}$ in $90 \%$ of patients with 1 day of apheresis when it is administered at 17 hours before collection..$^{22}$ This earlier time would allow administration within the normal business day before the next day's collection. Plerixafor is always used in combination with growth factor. The dose is $0.24 \mathrm{mg} / \mathrm{kg}$ via subcutaneous injection for creatinine clearance $(\mathrm{CrCl})$ greater than 50 $\mathrm{mL} / \mathrm{min}$, with a maximum dose of $40 \mathrm{mg} / \mathrm{d}$, and for $\mathrm{CrCl}$ of $50 \mathrm{~mL} / \mathrm{min}$ or less, the dose is $0.16 \mathrm{mg} / \mathrm{kg}$, with a maximum dose of $27 \mathrm{mg} / \mathrm{d}$. Doses may be given for up to 4 consecutive days. ${ }^{53}$
Considerable effort has been made to study what factors would predict a low stem cell yield, so that plerixafor could be added "on demand," "just in time," or as a "rescue." For example, one group correlated the peripheral blood CD34 cell count on day 4 or 5 of growth factor with the yield of progenitor cells after leukapheresis. ${ }^{54}$ A count of $11,17,21$, or $28 / \mathrm{mcL}$ corresponded with yields of $2,4,8$, or $12 \mathrm{x}$

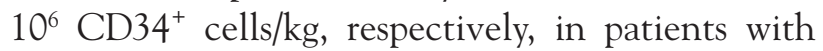
multiple myeloma and 6 or $15 / \mathrm{mcL}$ corresponded to yields of 2 or $4 \times 10^{6} \mathrm{CD} 34^{+}$cells/kg in patients with NHL. Furthermore, a first-day yield of less than $0.8 \mathrm{x}$ $10^{6} \mathrm{CD} 34^{+}$cells $/ \mathrm{kg}$ was correlated with an ultimate yield of less than $2 \times 10^{6} \mathrm{CD} 34^{+}$cells/kg. These types of correlations have led to institutional standards regarding when to use plerixafor in a risk-based approach; for instance, if the $\mathrm{CD} 34^{+}$cell count is less than $10 / \mathrm{mcL}$ with a target of greater than $2.5 \times 10^{6}$ $\mathrm{CD} 34^{+}$cells $/ \mathrm{kg}$, then add plerixafor. ${ }^{55}$ Using this same count of less than 10/mcL, Gopal et $\mathrm{al}^{22}$ showed that $87 \%$ of patients with lymphoma or myeloma achieved a target yield of progenitor cells with the addition of plerixafor. A retrospective comparison of G-CSF plus plerixafor versus chemotherapy plus G-CSF versus G-CSF plus GM-CSF as a remobilization regimen demonstrated the following success rates: $84 \%, 60 \%$, and $79 \%$, respectively, with the ability to collect $53 \%, 20 \%$, and $28 \%$, respectively, in a single day. ${ }^{56}$ The relative total costs of drugs plus leukapheresis for these 3 approaches revealed that the total costs were comparable for G-CSF plus plerixafor versus chemotherapy plus G-CSF, but the cost was approximately $40 \%$ less for G-CSF plus GM-CSF $(P<.01)$. An extensive cost-effectiveness analysis of many studies by a panel of experts revealed differences in effectiveness, quality of life, and cost among many regimens and algorithms, and the conclusion was to propose a more uniform center-specific prospective approach to examine these issues. ${ }^{57}$ Lastly, it has been shown that even after a prior mobilization attempt with plerixafor, repeat mobilization with plerixafor can be successful. ${ }^{58}$

\section{Allogeneic Donor Stem Cell Mobilization}

The most common method for mobilization of normal donors is G-CSF at doses in the range of 10 to $16 \mathrm{mcg} / \mathrm{kg} / \mathrm{d}$ via subcutaneous administration followed by leukapheresis beginning on day 4 or $5.31,59,60$ 
Approximately $80 \%$ of allogeneic donors are able to achieve target cell doses with mobilization. ${ }^{61}$ GM-CSF has also been shown to be effective, ${ }^{62}$ as has a tandem combination of GM-CSF followed by G-CSF. ${ }^{63}$ Typically, 1 or 2 apheresis procedures are sufficient, but occasionally inadequate collections occur for several reasons, such as larger size of recipient, high cell number needed for graft manipulation, or missed doses of G-CSF. Plerixafor also augments stem cell mobilization in healthy donors, although this is currently not an approved indication. ${ }^{64}$

The donor cell product is known to have a higher number of $\mathrm{T}$ lymphocytes when harvested from a leukapheresis collection compared with a bone marrow harvest, and a theoretical concern existed regarding which product might be superior in the unrelated donor setting, where the risk of GVHD might be increased. Therefore, a randomized trial compared the outcomes for PBPCs versus bone marrow as the source for patients undergoing unrelated donor transplantation. ${ }^{20}$ No differences in overall survival rate at 2 years $(51 \%$ vs $46 \%$, respectively) or the incidence of acute GVHD were seen. However, differences were noted in the incidence of graft failure (3\% vs $9 \%$, respectively; $P=.002$ ) and chronic GVHD at 2 years $(53 \%$ vs $41 \% ; P=.01) .^{20}$ Thus, these differences in graft failure and chronic GVHD are balanced by the advantages of PBPCs, so that there is no difference in overall survival.

\section{Contamination of Mobilized Products by Tumor Cells}

Tumor cells have been identified in mobilized stem cell products, with wide variability from $0.01 \%$ to greater than $10 \% .{ }^{65}$ The kinetics of mobilization are also variable, and some reports have shown the tumor cells to be mobilized with the same kinetics as the hematopoietic progenitrs, and others have reported that there are different peaks of mobilization. One study showed that contamination was predictive of overall survival in multiple myeloma. ${ }^{66}$ Contamination by tumor has been a major problem for neuroblastoma, and was able to be reduced from $50 \%$ to no contamination by CD34 selection. ${ }^{67}$ Given the historical high rates of tumor contamination with GCSF mobilization, it is intriguing that a study of cell products mobilized by G-CSF and plerixafor showed that no contamination by myeloma cells occurred. ${ }^{50}$

\section{Adverse Events Associated With Mobilization}

The most common side effect of G-CSF is bone pain, with a reported incidence of $61 \%$ in patients ${ }^{25}$ and $97 \%$ in normal donors. ${ }^{68}$ Other issues include inflammation at the injection site, exacerbation of rheumatologic disorders, and sickle cell crisis, including fatal consequences. Several case reports exist of splenic rupture after growth factor administration in allogeneic donors, but a prospective study of 309 normal donors did not encounter splenic rupture, although reversible enlargement of the spleen to an average of 1.5 times (range, 0.6-2.6) the pretreatment size was seen on ultrasound. ${ }^{69}$ A case of pulmonary hemorrhage was also reported in a normal donor. ${ }^{70}$ Another theoretical concern has been the possible contribution of G-CSF to the development of hematologic malignancies, and large studies of normal donors have not revealed a definitive risk. One group prospectively examined for chromosomal instability in normal donors who received G-CSF and found no abnormalities. ${ }^{71}$

\section{Biosimilars}

Tbo-filgrastim, originally designated $\mathrm{XM02}$, is another recombinant G-CSF that gained FDA approval in August 2012 based on conventional phase III trials demonstrating efficacy, and not according to the regulations permitting approval of biosimilars. Tbofilgrastim is indicated to reduce the duration of severe neutropenia in patients with nonmyeloid malignancies receiving myelosuppressive chemotherapy drugs associated with a clinically significant incidence of febrile neutropenia. Tbo-filgrastim is approved as a biosimilar G-CSF (Ratiograstim or Tevagrastim) in Europe, and has been shown in clinical trials overseas to be effective in mobilizing progenitor cells in patients ${ }^{72}$ and healthy donors, ${ }^{73}$ but it is not approved for this indication in the United States. In the future, as biosimilars become common, they may effectively reduce the cost of mobilization. However, given the relatively short experience with biosimilar drugs, the World Marrow Donor Association currently cautions against the use of biosimilars for unrelated donors unless this use is part of a clinical trial assessing safety. ${ }^{74}$

\section{Conclusions}

Strategies for hematopoietic progenitor cell collection from patients and donors are highly successful, 
albeit very costly. Which patients might benefit most from plerixafor, or who may even use the agent in a rescue strategy, can now be predicted, thus optimizing the cost-effectiveness. The role of biosimilar myeloid growth factors in mobilization has yet to be defined. Novel growth factors and small molecule inhibitors, and combinations of these agents, continue to be studied in the laboratory and clinical trials. The ideal strategy will result in a high stem/ progenitor cell yield with minimal toxicity during procurement, a product with reduced tumor cell contamination, and enhanced graft-versus-tumor effect with minimal GVHD. Recently published consensus guidelines for stem cell mobilization ${ }^{75}$ can serve as an additional resource.

\section{References}

1. Sugiyama $T$, Kohara $H$, Noda M, Nagasawa T. Maintenance of the hematopoietic stem cell pool by CXCL12-CXCR 4 chemokine signaling in bone marrow stromal cell niches. Immunity 2006;25:977-988.

2. Méndez-Ferrer S, Michurina TV, Ferraro F, et al. Mesenchymal and haematopoietic stem cells form a unique bone marrow niche. Nature 2010;466:829-834

3. Ding L, Saunders TL, Enikolopov G, Morrison SJ. Endothelial and perivascular cells maintain haematopoietic stem cells. Nature 25;481:457462.

4. Peled A, Petit I, Kollet $O$, et al. Dependence of human stem cell engraftment and repopulation of NOD/SCID mice on CXCR4. Science 1999;283:845-848

5. Carstanjen D, Gross A, Kosova N, et al. The alpha4beta1 and alpha5betal integrins mediate engraftment of granulocyte-colony-stimulating factor-mobilized human hematopoietic progenitor cells. Transfusion 2005;45:1192-1200.

6. Papayannopoulou T, Nakamoto B . Peripheralization of hemopoietic progenitors in primates treated with anti-VLA4 integrin. Proc Natl Acad Sci U S A 1993;90:9374-9378.

7. Avigdor A, Goichberg P, Shivtiel S, et al. CD44 and hyaluronic acid cooperate with SDF-1 in the trafficking of human CD34+ stem/progenitor cells to bone marrow. Blood 2004;103:2981-2989.

8. Levesque JP, Hendy J, Takamatsu Y, et al. Disruption of the CXCR4/ CXCL12 chemotactic interaction during hematopoietic stem cell mobilization induced by GCSF or cyclophosphamide. J Clin Invest 2003;111:187-196.

9. Levesque JP, Takamatsu Y, Nilsson SK, et al. Vascular cell adhesion molecule-1 (CD106) is cleaved by neutrophil proteases in the bone marrow following hematopoietic progenitor cell mobilization by granulocyte colony-stimulating factor. Blood 2001;98:1289-1297.

10. Ponte AL, Ribeiro-Fleury $\mathrm{T}$, Chabot $\mathrm{V}$, et al. Granulocyte-colonystimulating factor stimulation of bone marrow mesenchymal stromal cells promotes CD34+ cell migration via a matrix metalloproteinase-2dependent mechanism. Stem Cells Dev 2012;21:3162-3172.

11. Steinl C, Essl M, Schreiber TD, et al. Release of matrix metalloproteinase-8 during physiological trafficking and induced mobilization of human hematopoietic stem cells. Stem Cells Dev 2013;22:1307-1318.

12. Carion A, Benboubker L, Herault $\mathrm{O}$, et al. Stromal-derived factor 1 and matrix metalloproteinase 9 levels in bone marrow and peripheral blood of patients mobilized by granulocyte colony stimulating factor and chemotherapy. Relationship with mobilizing capacity of haematopoietic progenitor cells. Br J Haematol 2003;122:918-926.

13. Carstanjen $D$, Ulbricht $N$, Iacone $A$, et al. Matrix metalloproteinase- 9 (gelatinase B) is elevated during mobilization of peripheral blood progenitor cells by G-CSF. Transfusion 2002;42:588-596.

14. van Os R, van Schie ML, Willemze R, Fibbe WE. Proteolytic enzyme levels are increased during granulocyte colony-stimulating factor-induced hematopoietic stem cell mobilization in human donors but do not predict the number of mobilized stem cells. J Hematother Stem Cell Res 2002;11:513-521.

15. Domanovic D, Wozniak G, Cernelc P, et al. Matrix metalloproteinase-9 and cell kinetics during the collection of peripheral blood stem cells by leukapheresis. Transfus Apher Sci 2005;33:37-45.

16. Heissig, B, Lund LR, Akiyama $\mathrm{H}$, et al. The plasminogen fibrinolytic pathway is required for hematopoietic regeneration. Cell Stem Cell 2007;1:658-670

17. Li S, Zhai $\mathrm{Q}$, Zou $\mathrm{D}$, et al. A pivotal role of bone remodeling in granulocyte colony stimulating factor induced hematopoietic stem/progenitor cell mobilization. J Cell Physiol 2013;228:1002-1009.

18. Spiegel, A, Shivtiel S, Kalinkovich A, et al. Catecholaminergic neurotransmitters regulate migration and repopulation of immature human CD34+ cells through Wnt signaling. Nat Immunol 2007;8:1123-1131.

19. Lucas D, Battista M, Shi PA, et al. Mobilized hematopoietic stem cell yield depends on species-specific circadian timing. Cell Stem Cell 2008;3:364-366.

20. Anasetti C, Logan BR, Lee SI, et al; Blood and Marrow Transplant Clinical Trials Network. Peripheral-blood stem cells versus bone marrow from unrelated donors. N Engl J Med 2012;367:1487-1496.

21. Pesek G, Cottler-Fox M. Hematopoietic stem cell mobilization: a clinical protocol. Methods Mol Biol 2012;904:69-77.

22. Gopal AK, Karami M, Mayor J, et al. The effective use of plerixafor as a real-time rescue strategy for patients poorly mobilizing autologous CD34(+) cells. J Clin Apher 2012;27:81-87.

23. Bensinger W, Singer J, Appelbaum F, et al. Autologous transplantation with peripheral blood mononuclear cells collected after administration of recombinant granulocyte stimulating factor. Blood 1993; 81:3158-3163.

24. Kroger N, Zeller W, Fehse N, et al. Mobilizing peripheral blood stem cells with high dose G-CSF alone is as effective as with Dexa-BEAM plus G-CSF in lymphoma patients. Br J Haematol 1998;102:1101-1106.

25. Jillella AP, Ustun C. What is the optimum number of CD $34+$ peripheral blood stem cells for an autologous transplant? Stem Cells Dev 2004;13:598-606.

26. Wuchter P, Ran D, Bruckner T, et al. Poor mobilization of hematopoietic stem cells-definitions, incidence, risk factors, and impact on outcome of autologous transplantation. Biol Blood Marrow Transplant 2010;16:490-499.

27. Desikan KR, Tricot G, Munshi NC, et al. Preceding chemotherapy, tumour load and age influence engraftment in multiple myeloma patient mobilized with granulocyte colony-stimulating factor alone. Br J Haematol 2001;112:242-247.

28. Pusic I, Jiang SY, Landua $S$, et al. Impact of mobilization and remobilization strategies on achieving sufficient stem cell yields for autologous transplantation. Biol Blood Marrow Transplant 2008;14:1045-1056.

29. Gertz MA, Wolf RC, Micallef IN, Gastineau DA. Clinical impact and resource utilization after stem cell mobilization failure in patients with multiple myeloma and lymphoma. Bone Marrow Transplant 2010; 45:1396-1403.

30. Pavone V, Gaudio F, Console G, et al. Poor mobilization is an independent prognostic factor in patients with malignant lymphomas treated by peripheral blood stem cell transplantation. Bone Marrow Transplan 2006;37:719-724

31. Hosing C. Hematopoietic stem cell mobilization with G-CSF. Methods Mol Biol 2012;904:37-47.

32. Bolwell BJ, Pohlman B, Rybicki L, et al. Patients mobilizing large number of CD34+ cells ('super mobilizers') have improved survival in autologous stem cell transplantation for lymphoid malignancies. Bone Marrow Transplant 2007;40:437-441.

33. Kobbe G, Bruns I, Fenk R, et al. Pegfilgrastim for PBSC mobilization and autologous haematopoietic SCT. Bone Marrow Transplant 2009;43:669677.

34. Costa LJ, Kramer C, Hogan KR, et al. Pegfilgrastim- versus filgrastimbased autologous hematopoietic stem cell mobilization in the setting of preemptive use of plerixafor: efficacy and cost analysis. Transfusion 2012;52:2375-2381.

35. To LB, Shepperd KM, Haylock DN, et al. Single high doses of cyclophosphamide enable the collection of high numbers of hemopoietic stem cells from the peripheral blood. Exp Hematol 1990;18:442-447.

36. Haynes A, Hunter A, McQuaker G, et al. Engraftment characteristics of peripheral blood stem-cells mobilized with cyclophosphamide and the delayed addition of GCSF. Bone Marrow Transplant 1995;16:359-363.

37. Copelan EA, Ceselski SK, Ezzone SA, et al. Mobilization of peripheralblood progenitor cells with high-dose etoposide and granulocyte colony-stimulating factor in patients with breast cancer, non-Hodgkin's lymphoma, and Hodgkin's disease. J Clin Oncol 1997;15:759-765.

38. Linker CA, Owzar K, Powell B, et al; Cancer and Leukemia Group B. Auto-SCT for AML in second remission: CALGB study 9620. Bone Marrow Transplant 2009;44:353-359. 
39. Gisselbrecht C, Glass B, Mounier N, et al. Salvage regimens with autologous transplantation for relapsed large B-cell lymphoma in the rituximab era. J Clin Oncol 2010;28:4184-4190.

40. Barlogie B, Anaissie E, van Rhee F, et al. Incorporating bortezomib into upfront treatment for multiple myeloma: early results of total therapy $3 . \mathrm{Br}$ J Haematol 2007;138:176-185.

41. Popat U, Saliba R, Thandi R, et al. Impairment of filgrastim-induced stem cell mobilization after prior lenalidomide in patients with multiple myeloma. Biol Blood Marrow Transplant 2009;15:718-723.

42. Malard F, Kröger N, Gabriel IH, et al. Plerixafor for autologous peripheral blood stem cell mobilization in patients previously treated with fludarabine or lenalidomide. Biol Blood Marrow Transplant 2012;18:314-317

43. Pozotrigo M, Adel N, Landau $\mathrm{H}$, et al. Factors impacting stem cell mobilization failure rate and efficiency in multiple myeloma in the era of novel therapies: experience at Memorial Sloan Kettering Cancer Center Bone Marrow Transplant 2013;48:1033-1039.

44. Desikan KR, Barlogie B, Jagannath $S$, et al. Comparable engraftment kinetics following peripheral-blood stem-cell infusion mobilized with granulocyte colony-stimulating factor with or without cyclophosphamide in multiple myeloma. J Clin Oncol 1998;16:1547-1553.

45. Cooper DL, Proytcheva M, Medoff E, et al. Successful collection and engraftment of autologous peripheral blood progenitor cells in poorly mobilized patients receiving high-dose granulocyte colony-stimulating factor. J Clin Apher 2012;27:235-241.

46. Boeve S, Strupeck J, Creech S, Stiff PJ. Analysis of remobilization success in patients undergoing autologous stem cell transplants who fail an initial mobilization: risk factors, cytokine use and cost. Bone Marrow Transplant 2004;33:997-1003,

47. Donzella GA, Schols D, Lin SW, et al. AMD3100, a small molecule inhibitor of HIV-1 entry via the CXCR4 co-receptor. Nat Med 1998;4:72-77.

48. Liles WC, Broxmeyer HE, Rodger E, et al. Mobilization of hematopoietic progenitor cells in healthy volunteers by AMD3100, a CXCR4 antagonist. Blood 2003;102:2728-2730.

49. DiPersio JF, Micallef IN, Stiff PJ, et al; 3101 Investigators. Phase IIl prospective randomized double-blind placebo-controlled trial of plerixafor plus granulocyte colony-stimulating factor compared with placebo plus granulocyte colony-stimulating factor for autologous stem-cell mobilization and transplantation for patients with non-Hodgkin's lymphoma. J Clin Oncol 2009;27:4767-4773.

50. Tricot G, Cottler-Fox MH, Calandra G. Safety and efficacy assessment of plerixafor in patients with multiple myeloma proven or predicted to be poor mobilizers, including assessment of tumor cell mobilization. Bone Marrow Transplant 2010;45:63-68.

51. Micallef IN, Stiff PJ, DiPersio JF, et al. Successful stem cell remobilization using plerixafor (mozobil) plus granulocyte colony-stimulating factor in patients with non-hodgkin lymphoma: results from the plerixafor NHL phase 3 study rescue protocol. Biol Blood Marrow Transplant 2009;15:1578-1586.

52. Harvey RD, Kaufman JL, Johnson HR, et al. Temporal changes in plerixafor administration and hematopoietic stem cell mobilization efficacy: results of a prospective clinical trial in multiple myeloma. Biol Blood Marrow Transplant 2013;19:1393-1395.

53. Mozobil [package insert], Cambridge, MA: Genzyme Corporation; 2013.

54. Sinha S, Gastineau D, Micallef I, et al. Predicting PBSC harvest failure using circulating CD34 levels: developing target-based cutoff points for early intervention. Bone Marrow Transplant 2011;46:943-949.

55. Abhyankar S, DeJarnette $S, A$ ljitawi O, et al. A risk-based approach to optimize autologous hematopoietic stem cell (HSC) collection with the use of plerixafor. Bone Marrow Transplant 2012;47:483-487.

56. Perkins JB, Shapiro JF, Bookout RN, et al. Retrospective comparison of filgrastim plus plerixafor to other regimens for remobilization after primary mobilization failure: clinical and economic outcomes. Am J Hematol 2012;87:673-677.

57. Shaughnessy P, Uberti J, Devine S, et al. Plerixafor and G-CSF for autologous stem cell mobilization in patients with NHL, Hodgkin's lymphoma and multiple myeloma: results from the expanded access program. Bone Marrow Transplant 2013;48:777-781.
58. Yuan S, Nademanee A, Krishnan A, et al. Second time a charm? Remobilization of peripheral blood stem cells with plerixafor in patients who previously mobilized poorly despite using plerixafor as a salvage agent. Transfusion 2013; 53:3244-3250.

59. Bensinger WI, Weaver CH, Appelbaum FR, et al. Transplantation of allogeneic peripheral blood stem cells mobilized by recombinant human granulocyte colony stimulating factor. Blood 1995;85:1655-1658.

60. Zaucha JM, Gooley T, Bensinger WI, et al. CD34 cell dose in granulocyte colony-stimulating factor-mobilized peripheral blood mononuclear cell grafts affects engraftment kinetics and development of extensive chronic graft-versus-host disease after human leukocyte antigen-identical sibling transplantation. Blood 2001;98:3221-3227.

61. Rinaldi C, Savignano C, Pasca S, et al. Efficacy and safety of peripheral blood stem cell mobilization and collection: a single-center experience in 190 allogeneic donors. Transfusion 2012;52:2387-2394.

62. Sohn SK, Kim JG, Seo KW, et al. GM-CSF-based mobilization effect in normal healthy donors for allogeneic peripheral blood stem cell transplantation. Bone Marrow Transplant 2002;30:81-86.

63. Lonial S, Akhtari M, Kaufman J, et al. Mobilization of hematopoietic progenitors from normal donors using the combination of granulocytemacrophage colony-stimulating factor and granulocyte colony-stimulating factor results in fewer plasmacytoid dendritic cells in the graft and enhanced donor $\mathrm{T}$ cell engraftment with Th1 polarization: results from a randomized clinical trial. Biol Blood Marrow Transplant 2013;19:460-467.

64. Hauge AW, Haastrup EK, Sengel $\varnothing v \mathrm{H}$, et al. Addition of plerixafor for CD34+ cell mobilization in six healthy stem cell donors ensured satisfactory grafts for transplantation. Transfusion 2013;54:1055-1058.

65. DiPersio JF, Ho AD, Hanrahan J, et al. Relevance and clinical implications of tumor cell mobilization in the autologous transplant setting. Biol Blood Marrow Transplant 2011;17:943-955.

66. Kopp HG, Yildirim S, Weisel KC, et al. Contamination of autologous peripheral blood progenitor cell grafts predicts overall survival after high-dose chemotherapy in multiple myeloma. J Cancer Res Clin Oncol 2009; 135:637-642.

67. Marabelle A, Merlin E, Halle P, et al. CD34+ immunoselection of autologous grafts for the treatment of high-risk neuroblastoma. Pediatr Blood Cancer 2011;56:134-142.

68. Miller JP, Perry EH, Price TH, et al. Recovery and safety profiles of marrow and PBSC donors: experience of the National Marrow Donor Program. Biol Blood Marrow Transplant 2008;14(9 Suppl):29-36.

69. Stiff PJ, Bensinger W, Abidi MH, et al. Clinical and ultrasonic evaluation of spleen size during peripheral blood progenitor cell mobilization by filgrastim: results of an open-label trial in normal donors. Biol Blood Marrow Transplant 2009;15:827-834.

70. Kopp HG, Horger M, Faul C, et al. Granulocyte colony-stimulating factor induced pulmonary hemorrhage in a healthy stem cell donor. J Clin Oncol 2007;25:3174-3175.

71. Hirsch B, Oseth L, Cain M, et al. Effects of granulocyte-colony stimulating factor on chromosome aneuploidy and replication asynchrony in healthy peripheral blood stem cell donors. Blood 2011;118:2602-2608.

72. Publicover A, Richardson DS, Davies A, et al. Use of a biosimilar granulocyte colony-stimulating factor for peripheral blood stem cell mobilization: an analysis of mobilization and engraftment. Br J Haematol 2013;162:107-111.

73. Schmitt M, Xu X, Hilgendorf I, et al. Mobilization of PBSC for allogeneic transplantation by the use of the G-CSF biosimilar XM02 in healthy donors. Bone Marrow Transplant 2013;48:922-925.

74. Shaw BE, Confer DL, Hwang WY, et al. Concerns about the use of biosimilar granulocyte colony-stimulating factors for the mobilization of stem cells in normal donors: position of the World Marrow Donor Association. Haematologica 2011;96:942-947.

75. Giralt S, Costa L, Schriber J, et al. Stem cell mobilization strategies to improve patient outcomes: consensus guidelines and recommendations. Biol Blood Marrow Transplant 2014;20:295-308. 